
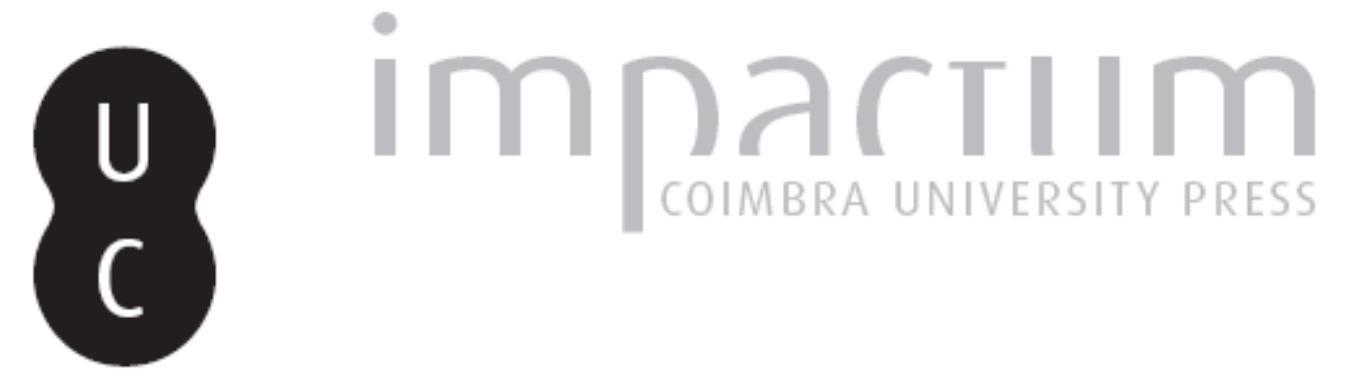

\title{
William Shakespeare (1564-1616)
}

Publicado por: Imprensa da Universidade de Coimbra

URL

persistente:

URI:http://hdl.handle.net/10316.2/43042

DOI:

DOI:https://doi.org/10.14195/1647-8436_46_47_20

Accessed : $\quad$ 26-Apr-2023 08:36:14

A navegação consulta e descarregamento dos títulos inseridos nas Bibliotecas Digitais UC Digitalis, UC Pombalina e UC Impactum, pressupõem a aceitação plena e sem reservas dos Termos e Condições de Uso destas Bibliotecas Digitais, disponíveis em https://digitalis.uc.pt/pt-pt/termos.

Conforme exposto nos referidos Termos e Condições de Uso, o descarregamento de títulos de acesso restrito requer uma licença válida de autorização devendo o utilizador aceder ao(s) documento(s) a partir de um endereço de IP da instituição detentora da supramencionada licença.

Ao utilizador é apenas permitido o descarregamento para uso pessoal, pelo que o emprego do(s) título(s) descarregado(s) para outro fim, designadamente comercial, carece de autorização do respetivo autor ou editor da obra.

Na medida em que todas as obras da UC Digitalis se encontram protegidas pelo Código do Direito de Autor e Direitos Conexos e demais legislação aplicável, toda a cópia, parcial ou total, deste documento, nos casos em que é legalmente admitida, deverá conter ou fazer-se acompanhar por este aviso.

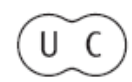




\section{BOLETIM DA \\ BIBLIOTECA GERAL DA UNIVERSIDADE DE COIMBRA}

VOL. 46/47 (2015/2016)

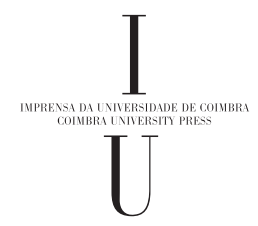




\section{William Shakespeare (1564-1616)}

\section{Sala do Catálogo da BGUC, Maio de 2016}

SHAKESPEARE, William, 1564-1616

As alegres comadres de Windsor : Impressas pela primeira vez em 1602, definitivamente em 1623, representadas talvez em 1601. Trad. de Domingos Ramos. Porto : Livraria Chardron, de Lello \& Irmão, 1913.

7-40-12-4

Amansia de uma fúria : Comédia em 5 actos. Trad. direta da edição de Collins por Henrique Braga. Porto : Lello \& Irmão, 1955.

$5-42-33$

António e Cleopatra : Tragédia : Traduzida diretamente da edição de Collins, a mais conforme à coleção Shakespeariana de Cambridge por Henrique Braga. Porto : Livraria Chardron, de Lelo \& Irmão, 1914.

6-6-6-31

Bem está o que bem acaba : Comédia em 5 actos. Tradução directa da edição de Collins por Henrique Braga. Porto : Livraria Lello \& Irmão; Lisboa : Aillaud \& Lellos, 1948.

$5-40-2$

A buen fin no hay mal principio: Trabajos de amor perdido. Buenos Aires : Espasa-Calpe Argentina, cop. 1946.

6-2-7-635 
Canseiras de amor baldadas : Comédia em 5 actos. Tradução directa da edição de Collins por Henrique Braga. Porto : Livraria Lello \& Irmão; Lisboa : Aillaud \& Lellos, 1948.

$5-40-2$

A comédia dos equívocos: Comédia em 5 actos. Traduzida directamente do original inglês por Henrique Braga. Porto : Lello \& Irmão, 1955.

$5-42-33$

Como lhe aprouver : Drama em 5 actos. Tradução de Henrique Braga. Porto : Lello \& Irmão, 1955.

$5-24-8$

Conto de Inverno: Comédia-Drama em 5 actos. Traduzida directamente da edição de Collins, a mais conforme com a célebre "Cambridge Shakespeare" por Henrique Braga. Porto : Lello \& Irmão, 1955.

$5-41-32$

Cymbeline : Drama romântico em 5 actos. Traduzido da edição de Collins por Henrique Braga. Porto : Lello \& Irmão, 1955.

5-42-33

Os dois cavalheiros de Verona : Comédia. Tradução directa da edição de Collins por Henrique Braga. Porto : Livraria Chardron, Lelo \& Irmão, 1914. 7-38-31-94

El-rei Henrique IV : Drama em 5 actos. Traduzida directamente da edição de Collins, a mais conforme com a célebre "Cambridge Shakespeare" por Henrique Braga. Porto : Livraria Lello \& Irmão; Lisboa : Aillaud \& Lellos, [1950?].

5-44-3

El-rei João : King John : Tragédia em 5 actos. Traduzida directamente da edição de Collins, a mais conforme com a célebre "Cambridge Shakespeare" por Henrique Braga. Porto : Lello \& Irmão, 1955. 
Hamlet : Drama em cinco actos. Tradução portuguesa [por el-rei D. Luís. Lisboa : Imprensa Nacional, 1877.

$7-42-12-22$

Hamlet : Drama em cinco actos. Traduzido para português por D. Luis de Bragança. Porto : Lello \& Irmão, 1956.

$5-24-31$

Hamlet : Publicado pela primeira vez em 1603 e definitivamente em 1604. Data da representação é incerta. Tradução de Domingos Ramos. Porto : Livraria Chardron, 1911.

6-1-12

Hamlet : Tragédia em 5 actos. Versão de Santos Quintella. 2a ed. Porto : Escriptorio de Publicações de J. Ferreira dos Santos, 1913. 6-6-6-34

Henrique IV. Tradução de Carlos Alberto Nunes. São Paulo : Editôra Cultura Popular, 1950.

5-43-32

Júlio César. Impresso pela primeira vez no in-folio de 1623 , representado provavelmente entre 1600, 1603 ou 1607. Trad. de Domingos Ramos. Porto : Livraria Chardron, 1913.

7-36-30-50

Macbeth : tragedia de Guilherme Shakespeare. Adaptada ao theatro moderno por Julio Carcano. Rio de Janeiro : [s.n.], 1871.

5-3-1

Macbeth. Trad. e enc. de António Pedro. [Porto] : Edição do Círculo de Cultura Teatral, imp. 1956.

$5-34-25$ 
Medida por medida : Trágico comédia em 5 actos. Tradução de Henrique Braga. Porto : Lello \& Irmão, 1955.

\section{5-24-8}

O mercador de Veneza. : Drama em cinco actos. Traducção livre. Lisboa : Imprensa Nacional, 1879.

$\mathrm{R}-36-42$

O mercador de Veneza. Tradução por Bulhão Pato. Lisboa : [s.n.], 1881. 7-44-18-28.

O mercador de Veneza. Rio de Janeiro : Annuario do Brasil, [1921]. 5-2-1

Muito barulho por nada : Comédia em 5 actos. Traduzida directamente da edição inglesa de Collins, da mais conforme com a célebre edição de Canterbury por Henrique Braga; revista por João Grave Porto : Livraria Chardron; Lisboa : Aillaud \& Bertrand, 1926.

5-26-16

Obras completas de William Shakespeare : Estudio preliminar, traduccion y notas por Luis Astrana Marin. Primera version integra del ingles, única edicion completa en lengua castellana. $4^{\text {a }}$ ed. Madrid : M. Aguilar, 1941.

$5-15-18-32$

Oeuvres complètes de W. Shakespeare. Trad. François Victor Hugo. 2nd ed. Paris : Pagnerre, Libraire Éditeur, 1865-1866.

7-44-24-1/18

Othello. Impresso pela primeira vez em 1622, representado em 1604. Tradução de Domingos Ramos. Porto : Livraria Chardron, 1911.

7-36-34-51 
Othello : Impresso pela primeira vez em 1862, representada em 1604. Trad. Domingos Ramos. $3^{a}$ ed. largamente emendada. Porto : Livraria Chardron, Lélo \& Irmão, 1925.

6-1-12

Othello de Shakespeare. Tradution de F.V.-Hugo entièrement refondue par Christine et René Lalou ; mise en scène et commentaires de Constantin Stanislavski ; traduits du russe par Nina Gourfinkel ; préface de Pierre-Aimé Touchard. Paris : Éditions du Seul, cop. 1948.

820-2 Shakespeare

Othello ou O mouro de Veneza : tragédia em 5 actos. Tradução de José António de Freitas. Lisboa : Avelino Fernandes Editores, 1882.

V.T.-18-1-6

Péricles, Príncipe de Tiro : drama romântico. Traduzida directamente da edição inglesa de William Collins, a mais conforme com a célebre "Cambridge Shakespeare" e revisto por João Grave. Porto : Livraria Chardron, Lélo \& Irmão, 1918.

820-2 Shakespeare SHA

The plays of William Shakspeare : in six volumes. London : printed for T. Longman, B. Law, C. Dilly ... [et al.], 1797. 6 vol.

1-4-6-354 / 1-4-6-359

O Rei Henrique V: Tragédia histórica em 5 actos. Tradução directa do inglês por Henrique Braga. Porto : Lello \& Irmão, 1955.

$5-42-33$

O Rei Henrique VI : Terceira parte : Tragédia em 5 actos. Traduzida directamente da edição de Collins, a mais conforme com a célebre "Cambridge Shakespeare" por Henrique Braga. Porto : Lello \& Irmão, 1955.

$5-42-33$ 
O Rei Henrique VIII : Tragédia em 5 actos. Tradução da edição Cassell por Henrique Braga. Porto : Lello \& Irmão, 1955.

$5-42-33$

O Rei Lear. Tradução segundo o texto da edição inglesa The Arden Shakespeare de 1936. Introdução e notas de Manuel Vieira. [S.I.] : Editorial Saber, imp. 1943.

5-30-8

O Rei Ricardo III. Tradução directa do inglês por Henrique Braga. Porto : Lello \& Irmão, 1955.

$5-24-8$

Ricardo III : Drama histórico em cinco actos. Lisboa : Imprensa Nacional, 1880. 7-42-12-1

Romeu e Julieta. Impresso pela primeira vez em 1597, data provável da representação 1596. Tradução de Domingos Ramos. Porto : Livraria Chardron, 1911.

6-1-12

Roméo et Juliette ; Hamlet. Tradution de François Victor Hugo ; entièrement revue et annotée par Christine et René Lalou. Paris : Éditions de Cluny, imp. 1939.

820-2 Shakespeare SHA

Romeu e Julieta. Tradução de Maria José Martins. Lisboa : Publicações Europa-América, imp. 1955.

5-49-11

The taming of the shrew. Introduction by Robert Atkins; Designs by May Néama. [London] : The Folio Society, 1960.

RC-21-11 
Tímon de Atenas : Tragédia. Tradução directa da edição de Collins por Henrique Braga. Porto : Livraria Chardron, de Lelo \& Irmão, 1913. 6-6-6-32

Tito Andronico : Tragédia em 5 actos. Trad. de Henrique Braga. Porto : Lello \& Irmão, 1955.

$5-24-8$

A tragédia de Julio César $=$ The tragedy of Julius Caesar. Tradução em verso e prosa, conforme o original, introdução e anotações por Luíz Cardim.

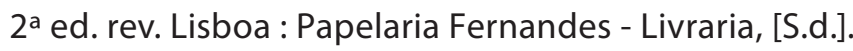

$5-42-9$

Tróilo e Créssida : tragicomédia. Traduzida directamente da edição de Collins por Henrique Braga. Porto : Lello \& Irmão, 1955.

$5-24-8$

Venus \& Adonis. Designed and drawn by Peter Rudland. London : W. H. Allen, 1948.

5-22-13-87

Vida e morte d'el-rei Ricardo II : Tragédia. Traduzida directamente da edição inglesa de William Collins, a mais conforme com a célebre "Cambridge Shakespeare" por Henrique Braga. Porto : Livraria Chardron, 1915.

6-6-6-33

\section{Bibliografia passiva}

ASOCIACION de Estudiantes de Arquitectura del Tecnologico de Monterrey.

Los sonetos de Shakespeare. Monterrey : Sierra Madre, 1959.

IC-16-1-2-80

AVELAR, Mário, 1956-

O essencial sobre William Shakespeare. $1^{1 \mathrm{a}} \mathrm{ed}$. Lisboa : Imprensa Nacional-Casa da Moeda, imp. 2012. 


\section{BALLESTER ESCALAS, Rafael}

El historiador William Shakespeare : (ensayo sobre el espíritu del siglo XVI).

Tarragona : Editorial R. Ballester, 1945.

820.06 Shakespeare BAL

BERTHELOT, René, 1872-

La sagesse de Shakespeare et de Goethe. $3^{\mathrm{a}}$ ed. Paris : Librairie Gallimard-

Nouvelle Revue Française, 1930.

820.06 Shakespeare BER

BROWER, Reuben Arthur

Hero and saint : Shakespeare and the Graeco-Roman heroic tradition. Ox-

ford : Clarendon Press, 1971.

5-11-73-108

BRYSON, Bill, 1951-

Shakespeare. Trad. Vítor Antunes. Lisboa : Bertrand, 2008.

9-(1)-11-14-3

BRUNEL, Pierre

Claudel et Shakespeare. Paris : Librairie Armand Colin, 1971.

5-46-74-20

CARDIM, Luís, 1879-1958

Shakespeare e o drama inglês. Porto : Faculdade de Letras, 1931.

IC-18-2-5-49

CAZAMIAN, Louis François, 1877-1965

L'humour de Shakespeare. Paris : Aubier-Éditions Montaigne, imp. 1945.

820.06 Shakespeare CAZ

CECIL, David, 1902-1986

Antony and Cleopatra : the fourth W.P. Ker Memorial Lecture delivered

in the University of Glasgow, 4th May 1943. Glasgow : Jackson, 1944.

5-23-38 
CHAMBERS, E. K., Sir

Sources for a biography of Shakespeare. Oxford : Clarendon Press, [imp. 1970].

5-39-59-17

COLÓQUIO sobre Shakespeare, Lisboa ; FLOR, João Almeida, ed. lit. Colóquio sobre Shakespeare. Lisboa : F.C.G., Acarte, 1990.

6-8-22-13

COLÓQUIO Shakespeare Entre Nós, Lisboa ; SERÔDIO, Maria Helena, ed. lit. Shakespeare entre nós. $1^{\text {a }}$ ed. Lisboa : CEAUL : CET, 2009.

10-(1)-1-4-61

DANTAS, Júlio, 1876-1962

Rei Lear : Adaptação em 7 quadros e em verso da tragédia em 28 scenas e em prosa, de Shakespeare. 2. ed. Lisboa : Portugal - Brasil, [192-?].

$5-3-26$

DEELMAN, Christian

The great Shakespeare Jubilee. London : Michael Joseph, cop. 1964.

6-11-21-33

DEMBLON, Célestin, 1859-1924

Lord Rutland est Shakespeare : le plus grand des mystères dévoilé Shaxper de Stratford hors cause. Paris : Paul Ferdinando, 1913.

8-(2)-15-2-1

FALCONER, Alexander Frederick

Shakespeare and the sea. London : Constable, 1964.

6-11-13-9

FORJAZ, António Pereira, 1893-1972

Presença de Shakespeare : discurso... Lisboa : Academia das Ciências de Lisboa, 1964.

5-12-17-96 
FOX, Levi

The Shakespeare anniversary book. Norwich : Jarrold and Sons, [1964?]

7-69-8-24

FROST, David Leonard, 1939-

The school of Shakespeare : the influence of Shakespeare on English drama : 1600-42. Cambridge : University Press, 1968.

$6-11-21-8$

GRILO, Monteiro

A modernidade de Shakespeare. Lisboa : Edições Brotéria, 1965.

5-47-23-114

HALLIDAY, F. E.

The life of Shakespeare. London : Geral Duckworth, cop. 1961.

6-11-13-23

HARRISON, G. B.

Shakespeare. London : Ernest Benn Lda, imp. 1938.

7-77-5-19

HARTNOLL, Phyllis

Shakespeare in music. London [etc.] : Macmillan ; New York : St. Martin's Press, 1966.

MI-1-5-39

HAWKINS, Harriett

The devil's party : critical counter-interpretations of Shakespearian drama.

Oxford : Clarendon Press, 1985.

5-22-38-43

HINMAN, Charlton.

The printing and proof-reading first folio of Shakespeare. Oxford: At the Clarendon Press, 1963.

5-10 B-4-11 
HOLLAND, Norman N. ; HOMAN, Sidney ; PARIS, Bernard J.

Shakespeare's personality. Berkeley, [etc.] : University of California Press, 1989.

7-61-7-37

INTERPRETATIONS of Shakespeare : British Academy Shakespeare Lectures.

Select. by Kenneth Muir. Oxford : Clarendon Press, 1985.

$5-22-38-10$

JAY, Roni

Shakespeare. Trad. Luiza Mascarenhas. Mem Martins : Europa-América, imp. 2003.

$6-48-2-28$

JOSEPH, Miriam, Sister

"Hamlet", a Christian tragedy. Sep. de: Studies in Philology. $59: 2$ (Apr. 1962) 119-140.

$5-6-73-155$

KNIGHT, George Wilson, 1897-

Shakespearian production : with especial reference to the tragedies. London : Routledge and Kegan Paul, [1968].

5-46-71-1

LAMB, Charles, 1775-1834 ; LAMB, Mary, 1764-1847

Tales from Shakespeare : selected for use in schools. New edition reset. London : G. Bell and Sons, 1918.

820-32 Lamb LAM

LOWERS, James K.

Hamlet [de] Shakespeare. Trad. Mário Matos. Mem Martins : Publicações

Europa-América, D.L. 1991.

6-48-7-101 
MOUTINHO, José Viale, 1945-

A história de William : a possível infância de Shakespeare. Il. José Emídio.

$1^{\text {a }}$ ed. Porto : Campo das Letras, 2005.

9-71-1-115

NOBLE, Richmond

Shakespeare's : use of song with the text of the principal songs. Oxford :

Clarendon Press, prt. 1967.

5-38-2

SCOTT-GILES, Charles

Wilfrid Shakespeare's heraldry. London : J. M. Dent and Sons Ltd., prt. 1950. V.T.-8-1-15

SERÔDIO, Maria Helena

William Shakespeare : a sedução dos sentidos. $1^{\text {a }}$ ed. Lisboa : Cosmos, 1996.

6-49-7-4

SHOENBAUM, Samuel

Shakespeare's lives. New ed. Oxford : Clarendon Press, 1991.

7-63-9-36

SISSON, C. J.

Shakespeare. London : Published for the British Council, [1955].

7-40-2-105

SPENCER, T. J. B., 1915-1978

William Shakespeare : the roman plays. London : Published for the British

Council, 1963.

IC-18-4-4-31

SPURGEON, Caroline Frances Eleanor, 1869-1942

Keats's : Shakespeare : a descriptive study. Oxford : At the Clarendon Press, prt. 1968.

5-20-21 
STENDHAL, pseud.

Molière : Shakspeare : la comédie et le rire. Paris : Le Divan, 1930.

840.06 Molière STE

THALER, Alwin, 1981-

Shakespeare and Sir Philip Sidney : the influence of 'The Defense of Poesy'.

Cambridge, Mass. : Harvard University Press, 1947.

5-40-18

VIGLIONE, Anna G.

Shakespeare's Antony. Genova : Accademia Ligure di Scienze e Lettere, 1985. 7-49 A-6-21

WILLIAM Shakespeare. [Versão portuguesa de Ricardo Alberty]. [Lisboa] :

Editorial Verbo, cop. 1972.

5-58-33-11

WILLIAM Shakespeare : an exhibition of his work, with critical commentaries thereon and translations of the plays in the Library of the University of Coimbra. 12th- 17th May 1947. [S.I. : s.n.], 1947.

5-10 B-12-4-55

WINTER, Oswald, 1931-

Le Shakespeare na Europa. Trad. Isabel Veríssimo. Mem Martins : Europa-América, D.L. 2003.

6-46-1-81 